\title{
Efeitos da accountability na educação escolar no Ceará
}

RESUMO: $O$ artigo visa entender a influência da Reforma do Estado da década de 1990 nas políticas educacionais e os efeitos da accountability na rede escolar do Ceará, mediante análise documental e revisão de literatura. O governo estadual aderiu à lógica educacional da accountability: padronização, prestação de contas e responsabilização. Isso ocasionou efeitos perversos ao excluir uma parcela populacional vulnerável: jovens com 18 anos ou mais que frequentam o turno noturno.

PALAVRAS-CHAVE: Escola pública. Accountability. Políticas educacionais. Neoliberalismo.

\author{
Márcio Kleber Morais Pessoa \\ João Bosco Feitosa dos Santos
}

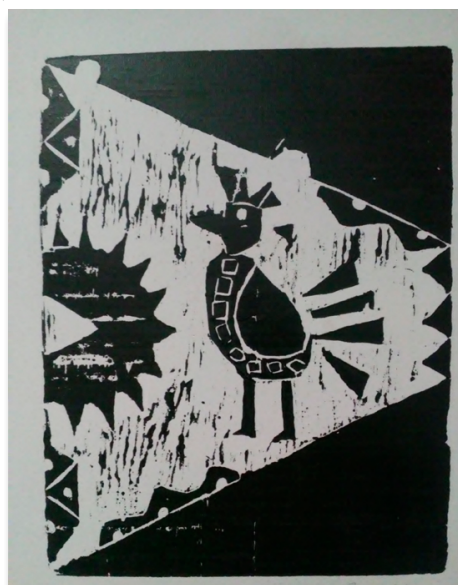

\section{Effects of accountability on school education in Ceará}

\section{Márcio Kleber Morais Pessoa}

Doutorando em Sociologia pelo Programa de Pós-Graduação em Sociologia da Universidade Estadual do Ceará (PPGS - UECE), mestre em Sociologia pelo Programa de Pós-Graduação em Sociologia da Universidade Federal do Ceará (PPGS - UFC).

E-mail: mkpceara@hotmail.com

\section{João Bosco Feitosa dos Santos}

Doutor em Sociologia pelo Programa de Pós-Graduação em Sociologia da Universidade Federal do Ceará (PPGS - UFC), pós- doutor em Ciências Sociais pela Universidade Estadual Paulista (Unesp) e professor do curso de Ciências Sociais e do Programa de Pós-Graduação em Sociologia da Universidade Estadual do Ceará (UECE). E-mail: feitosabosco@gmail.com
ABSTRACT: The article aims to understand the influence of the 1990s State Reform on educational policies and the effects of accountability in the school network of Ceará, through documentary analysis and literature review. The state government adhered to the educational logic of accountability: standardization, accountability, and liability. This caused perverse effects by excluding a vulnerable population portion: young people aged 18 years or older who attend the night shift.

KEYWORDS: Public school. Accountability. Educational policies. Neoliberalism.

RECEBIDO: $23 / 10 / 2019$

APROVADO: 28/08/2020 


\section{Introdução}

O objetivo deste texto é compreender as políticas públicas educacionais da rede estadual do Ceará por meio da noção de accountability, entendida como a associação entre avaliação, prestação de contas e responsabilização (AFONSO, 2009). Com isso, serão traçados aproximações e distanciamentos das políticas educacionais desse estado em relação às políticas de cunho neoliberal com as quais a noção de accountability se identifica. Para tanto, pretende-se entender a Reforma do Estado da década de 1990 e sua influência nas políticas públicas educacionais; analisar leis e outros documentos relacionados à educação escolar na rede estadual do Ceará, à luz da noção de accountability discutida; e compreender possíveis efeitos da accountability na educação escolar da rede estadual do Ceará.

Os procedimentos metodológicos empregados foram: primeiramente, análise documental (CELLARD, 2014) relacionada à educação escolar na rede estadual do Ceará e ao tema estudado. Entendendo o contexto de cada documento, quem o escreveu e em que circunstâncias foi escrito, exercita-se a tarefa de "desconstruí-lo", a fim de "reconstruí-lo" de maneira a analisá-lo em acordo com as teorias discutidas (CELLARD, 2014). Ademais, foi realizada revisão de literatura, o que possibilitou a discussão com outros autores que pensaram de alguma forma o tema aqui discutido.

\section{A Reforma do Estado da década de 1990: tentativa de serviço estatal eficiente?}

Após a Segunda Guerra Mundial, o Estado passou a ser visto como "fator de desenvolvimento econômico e social". Isso só foi possível com o "crescimento explosivo do Estado", aumentando seus tributos e o número de burocratas públicos (PEREIRA, 1997).

Todavia, a partir da década de 1970, com o advento da globalização, o Estado passou a ser percebido como um obstáculo ao crescimento econômico e à proteção social. Segundo Bresser Pereira (1997), o desenvolvimento tecnológico contribuiu para a concorrência internacional, o que levou países a competirem entre si de forma intensa. O país que não acumulasse características de 
competitividade dentro dessa nova lógica provavelmente perderia essa competição. Dito isso, estava em xeque a garantia à proteção social aos cidadãos pelo Estado, além da manutenção de um grande corpo burocrático estatal, o que inevitavelmente oneraria os empresários locais, dificultando, assim, suas condições de concorrer naquele novo cenário.

Apesar dos argumentos apresentados por Bresser Pereira (1997), que foi o principal responsável pela Reforma do Estado brasileiro ao atuar como ministro do governo FHC (1995 - 2002), importa ressaltar que o Brasil conta com uma carga tributária regressiva - ou injusta -, o que significa que os ricos pagam menos do que os pobres. Quanto mais se ganha, menos se paga em tributos. Em 2013, por exemplo, mais de 53\% da carga tributária bruta brasileira foi referente a bens e serviços, enquanto tributos sobre propriedade e sobre renda, lucro e ganhos de capital ficaram em torno de $22 \%$ do total. Isso indica que a justificativa de desonerar a classe proprietária visando a garantir seu potencial de competição no mercado internacional não é verdadeira, ainda mais se a base de incidência dos tributos brasileira for comparada com a dos países centrais do capitalismo, que taxam os ricos de forma bem mais severa. Nos EUA, por exemplo, aquelas porcentagens praticamente se invertem em relação ao Brasil. Já na Dinamarca, os tributos aos ricos chegam a quase $70 \%$ do total arrecadado (BRASIL, 2015).

Continuando, além da dita necessidade de meios para a saudável competição capitalista, os burocratas passaram a ser questionados em relação ao desenvolvimento dos serviços prestados, a saber:

\begin{abstract}
Na realização das atividades exclusivas de Estado e principalmente no oferecimento dos serviços sociais de educação e saúde, a administração pública burocrática [...] demonstrava agora ser ineficiente e incapaz de atender com qualidade as demandas dos cidadãos-clientes no grande Estado Social do século vinte (PEREIRA, 1997, p. 13).
\end{abstract}

Como se pode perceber, o papel do Estado estava sendo questionado, o que era agravado no Brasil pelo cenário hiperinflacionário do final da década de 1980 e início da de 1990. Para Pereira (1997), a globalização impôs uma dupla pressão sobre o Estado: 
[...] de um lado representou um desafio novo - o papel do Estado é proteger seus cidadãos, e essa proteção estava agora em cheque; de outro lado, exigiu que o Estado, que agora precisava ser mais forte para enfrentar o desafio, se tornasse também mais barato, mais eficiente na realização de suas tarefas, para aliviar o seu custo sobre as empresas nacionais que concorrem internacionalmente (PEREIRA, 1997, p. 14 - 15).

Nesse sentido, o Estado não poderia ser eliminado, tinha que ser reformado. Foi nesse contexto que o governo Fernando Henrique Cardoso efetivou a Reforma do Estado brasileiro, implementando uma administração pública gerencial em detrimento da forma burocrática então existente, que tinha custos crescentes, baixa qualidade e era ineficiente em relação aos serviços sociais (PEREIRA, 1997). Importa ressaltar que "o Banco Mundial e o Banco Interamericano de Desenvolvimento tornaram os empréstimos para a reforma do Estado prioritários" (PEREIRA, 1997, p. 17), o que indica forte interesse das organizações multinacionais capitalistas em materializar as transformações no Estado, destacadas acima. Isso ocorreu, porque esse tipo de reforma toma:

[...] como base a atividade econômica e a organização produtiva, o mercado, introduzindo a "cultura da empresa" no domínio da administração pública. Nesse quadro, a empresa moderna representa um modelo que deve ser seguido no que concerne à capacidade de resposta e de adaptação funcional às exigências do mercado (LIMA, 1997, p. 52, grifo do autor).

A adoção do que o autor chama de "cultura da empresa", ou gerencialismo, como princípio do serviço público floresceu na Inglaterra de Margareth Thatcher e nos Estados Unidos de Ronald Reagan:

Em ambos os países, o movimento gerencialista no setor público é baseado na cultura do empreendedorismo, que é um reflexo do capitalismo flexível e se consolidou nas últimas décadas por meio da criação de um código de valores e condutas que orienta a organização das atividades de forma a garantir controle, eficiência e competitividade máximos (PAULA, 2005, p. 38). 
A autora destaca que o gerencialismo enfatiza problemas do âmbito das finanças públicas, dos investimentos estatais (questões de natureza fiscal, tributária e monetária) e organizacional da gestão (planejamento, direção e controle das ações estatais) em detrimento da dimensão sociopolítica, que envolve a relação entre Estado e sociedade, direitos dos cidadãos e participação democrática na gestão (PAULA, 2005). Isso contribui para a dificuldade de fiscalização e controle social, "pois não há mecanismos para que esse controle ocorra, nem a transparência esperada" (PAULA, 2005, p. 43).

Uma das justificativas para a reforma gerencial do Estado foi a falta de governança do governo, isto é, a falta de "condições financeiras e administrativas para transformar em realidade as decisões que toma" (PEREIRA, 1997, p. 40). Dessa forma, além do ajuste fiscal, que visou a resolver o problema financeiro do Estado, a reforma gerencial visou a resolver o problema administrativo, a saber: "em um mundo em plena transformação tecnológica e social, é impossível para o administrador ser racional sem poder adotar decisões, sem usar de seu julgamento discricionário, seguindo cegamente os procedimentos previstos em lei" (PEREIRA, 1997, p. 41). O autor, portanto, desconsidera qualquer tipo de autonomia da burocracia ou sua capacidade de interpretação das leis vigentes. Todavia, um dos objetivos dessa reforma também foi esvaziar a burocracia pública de um certo poder estratégico, devido à sua importância central no tipo de Estado burocrático, a saber:

Ao mesmo tempo que a burocracia estatal, ou seja, o conjunto de administradores públicos profissionais, via sua posição estratégica na sociedade aumentar, ficava claro que se tornava necessário adotar novas formas de gestão da coisa pública, mais compatíveis com os avanços tecnológicos, mais ágeis, descentralizadas, mais voltadas para o controle de resultados do que o controle de procedimentos (PEREIRA, 1997, p. 41 - 42).

Como se pode apreender do trecho acima, a gestão pública passou a focar o resultado do trabalho do burocrata em detrimento de como essa atividade é realizada. Isso abriu espaço para a política de metas bastante universalizada nas burocracias públicas nos dias atuais, por exemplo. Nesse sentido, a racionalidade do Estado 
já não seria garantida pelo burocrata estatal, mas sim por processos de controle do resultado do trabalho daquele sujeito (em agências executivas), que seriam realizados pelo "núcleo estratégico do Estado" (PEREIRA, 1997, p. 43), uma alta cúpula estatal formada tanto pela alta burocracia como por membros do governo (secretarias formuladoras de políticas públicas). Sabendo disso, será discutida a seguir a influência dessa reforma nas políticas educacionais.

\section{A Reforma do Estado e a educação escolar}

Essas mudanças atingiram a escola pública em cheio, visto se tratar de uma das instituições mais ramificadas na sociedade. Dialogando com Melo (2008) acerca da realidade portuguesa em relação às transformações gerencialistas do Estado, que se aproxima da realidade brasileira, a adoção desses princípios de gestão pública identificados com o neoliberalismo fez o Estado assumir "progressivamente políticas de 'recentralização', de 'metaregulação' e de 'controlo remoto' que visam a responsabilização e a prestação de contas por parte dos professores e das escolas" (MELO, 2008, p. 11, grifo da autora). Isso significa dizer que escola e professores passaram a ser responsabilizados pela atuação dos alunos em avaliações estatais quantificadas e padronizadas. Isso ocorreu, principalmente, pela criação de avaliações em larga escala que passaram a ser o "termômetro" das escolas públicas, mas também das privadas, em algumas situações. É o caso do ENEM ${ }^{1} \mathrm{e}$ do $\mathrm{SAEB}^{2}$, em nível nacional, e do SPAECE ${ }^{3}$, no Ceará.

1 O Exame Nacional do Ensino Médio (ENEM) é realizado anualmente. Seus principais objetivos são: servir como parâmetro para selecionar alunos para o ensino superior e estabelecer ranking entre as escolas, como forma de prestação de contas. Disponível em: https://enem.inep.gov.br/. Acesso em: 04 mai. 2020. 2 "O Sistema de Avaliação da Educação Básica - Saeb, instituído em 1990, é composto por um conjunto de avaliações externas em larga escala e tem como principal objetivo realizar um diagnóstico da educação básica brasileira e de alguns fatores que possam interferir no desempenho do estudante, fornecendo um indicativo sobre a qualidade do ensino ofertado" (SISTEMA..., [2017?], [s.p.]). 3 O Sistema Permanente de Avaliação da Educação Básica do Ceará (SPAECE) "fornece subsídios para formulação, reformulação e monitoramento das políticas educacionais, vislumbrando a oferta de um ensino de qualidade a todos os alunos da rede pública do Ceará. Para isso, a cada edição, são aplicados testes de desempenho e questionários contextuais que possibilitam extrair 
Inicialmente, isso leva a um conflito inarredável, a saber: "Os docentes [...] têm, na verdade, de gerir diariamente no seu ofício várias imposições contraditórias [como, por exemplo] [...] promoverem o desenvolvimento integral dos discentes ${ }^{4}$ [e] [...] avaliar objetivamente os estudantes" (MELO, 2008, p. 11). A autora indica que as práticas dos professores portugueses revelam valorização dos condicionalismos a que se encontram cotidianamente sujeitos, em detrimento dos valores presentes em seus discursos. ${ }^{5}$ Nesse sentido, o saber passa "a ser progressivamente encarado como um 'instrumento' que tem de ser o mais rentabilizado possível, adquirindo o cunho utilitarista característico das exigências do mercado" (MELO, 2008, p. 14, grifo da autora).

Essa noção faz com que os professores portugueses passem a perceber os rankings como "julgamento público sobre o mundo escolar em geral, e sobre o seu desempenho" (MELO, 2008, p. 14). Ademais, as avaliações em larga escala generalizam "os procedimentos e valores típicos do capitalismo competitivo na gestão dos sistemas [de ensino] e das instituições educacionais" (SOUZA; OLIVEIRA, 2003, p. 874). Dito isso, a adoção de políticas gerencialistas pelo Estado na área educacional contribui para a centralização das avaliações, ao mesmo tempo em que se descentralizam os mecanismos de gestão e de financiamento (SOUZA; OLIVEIRA, 2003). Isso leva a um forte controle dos resultados educacionais, mas a uma fraca regulamentação dos processos educacionais, isto é, as gestões escolares passam a ter relativa liberdade de agir, introduzindo "melhorias", desde que alavanquem os resultados.

Essa lógica leva a uma disputa entre as escolas em busca de "qualidade", ou seja, as escolas são obrigadas a competir entre si pelas posições nos rankings, mesmo que haja enormes

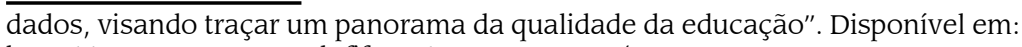
http://www.spaece.caedufjf.net/. Acesso em: 24 out. 2017.

4 No caso brasileiro, a Lei de Diretrizes e Bases da Educação Nacional dispõe, em seu Art. $2^{\circ}$, que a educação tem por finalidade "o pleno desenvolvimento do educando, seu preparo para o exercício da cidadania e sua qualificação para o trabalho" (BRASIL, 1996, [s.p.]).

5 Como complemento: "Questionados sobre os efeitos da implementação dos exames nacionais [...] nas suas práticas lectivas, 61,7\% dos professors inquiridos apontaram 'a impossibilidade de experimentar outras pedagogias' como a consequência mais nefasta" (MELO, 2008, p. 12). 
desigualdades entre elas: " "a crença é a de que as pressões geradas pela competição, suscitada pelos procedimentos avaliativos, farão com que sejam mobilizados processos e recursos que resultarão em melhoria da qualidade de ensino" (SOUZA; OLIVEIRA, 2003, p. 890). É a desigualdade gerando a "qualidade" ou, em outras palavras, para haver escolas bem posicionadas em rankings, é necessário que haja as mal posicionadas. Nesse sentido, as avaliações no Brasil:

[...] têm servido para viabilizar uma lógica de gerenciamento da educação, reconfigurando, por um lado, o papel do Estado e, por outro, a própria noção de educação pública, ao difundir uma ideia de qualidade que supõe diferenciações no interior dos sistemas públicos de ensino, como condição mesma de produção de qualidade (SOUZA; OLIVEIRA, 2003, p. 879).

Um dos fatores que contribuem para a consolidação desse cenário de desigualdade é a falta de suporte diferenciado para as escolas que não se saem bem nos testes padronizados. Ao contrário, geralmente há premiação ou estímulo às escolas bem colocadas, fomentando, assim, o espírito competitivo de estabelecimentos e sujeitos educacionais. Todavia, princípios e valores da iniciativa privada "trazem consigo um projeto de sociedade que certamente não contém a utopia da transformação [...] o que se evidencia com as práticas em curso é a perspectiva da reprodução e intensificação das desigualdades educacionais e sociais" (SOUZA; OLIVEIRA, 2003, p. 890).

Nessa perspectiva, sendo percebidas como critério de qualidade, as avaliações em larga escala tornam-se centrais para a configuração de políticas públicas educacionais (AFONSO, 2009). Mais especificamente, a accountability ${ }^{7}$ está se tornando central, mas também autônoma em relação às concepções político-ideológicas dos governos, visto ser ditada por organizações internacionais e supranacionais. ${ }^{8}$ Isso faz com que esse tipo de prática se situe:

6 Haguette, Pessoa e Vidal (2016) descobriram dois padrões de qualidade em escolas públicas da rede estadual do Ceará. Esse tipo de dado é desconsiderado em uma disputa entre estabelecimentos.

7 Entendida como avaliação, prestação de contas e responsabilização (cf. AFONSO, 2009). Essa discussão será aprofundada adiante.

8 Tais como a Organização para a Cooperação e o Desenvolvimento Econômico 
[...] acima das realidades culturais, políticas, económicas e educacionais nacionais. Esta tendência, entre outras consequências, tem aumentado a eficácia legitimadora destas políticas, tornando mais difícil desocultar os interesses, demandas e funções que lhe subjazem (AFONSO, 2009, p. 17).

Isso tem relação direta com a emergência do que Afonso (2009) chama de "Estado-avaliador", que se aproxima da noção de Estado regulador presente na Reforma do estado do governo FHC: a regulação por meio da avaliação. Afonso (2009) ainda destaca a falta de fundamentação política, cultural, ética, técnico-científica e educacional para a publicação de rankings de escolas e professores - mas, apesar disso, essa é a tendência do novo capitalismo. Se as escolas são diferentes - além de desiguais, em muitos casos -, ranqueá-las por meio de testes padronizados pode se caracterizar como uma incongruência. No Ceará, por exemplo, há escolas que têm propostas pedagógicas dissonantes em relação àquele tipo de teste, como é o caso, por exemplo, de Escolas Indígenas, Escolas Quilombolas, Escolas do Campo, Centros de Educação de Jovens e Adultos etc. Todavia, esses tipos de estabelecimentos compõem os rankings como todos os demais.

Além disso, o fato de as escolas públicas terem relativa liberdade para discutirem seus projetos político-pedagógicos abre margem para que sejam trabalhados conteúdos que "não contam" (LIMA, 1997) para os rankings e, consequentemente, para esse critério de "qualidade". Lima (1997) atribui isso exatamente à "ideologia gerencialista" e ao "ethos gestionário", que se expandiram pelo globo ignorando fronteiras geográficas e culturais. Haguette, Pessoa e Vidal (2016), por exemplo, encontraram uma escola do campo no grupo das escolas pior posicionadas no ranking do ENEM no estado do Ceará, ao realizarem uma pesquisa com o objetivo de criar uma tipificação ideal das escolas mal posicionadas no ranking. Essa escola do campo, porém, acabou sendo excluída dessa tipificação por se tratar de um caso desviante

(OCDE), a União Europeia (EU), o Banco Mundial (BM) e a Organização Mundial do Comércio (OMC), dentre outros (cf. AFONSO, 2009). 
dentre os demais estabelecimentos estudados, visto que tinha, em sua proposta pedagógica, o ensino de técnicas de plantio aos alunos, a fim de garantir sua continuidade e sobrevivência no campo. Apesar de ser uma proposta coerente com as demandas da comunidade, é um conteúdo que "não conta" para a medição dos rankings, como destacou Lima (1997), o que a insere no rol das piores escolas do estado.

Nesse sentido, publicados de forma acrítica, os rankings servem para a triagem de estabelecimentos pelas famílias dos alunos, seja entre escolas públicas e privadas - ocasionando "efeitos de mercado" - , seja somente entre escolas públicas, considerando as melhores e as piores colocadas - ocasionando "efeitos de quase-mercado" (AFONSO, 2009, p. 21). Isso pode levar à competição entre os estabelecimentos de ensino - os professores e os alunos -, fazendo com que adotem medidas para subirem ou manterem boas posições no ranking (MELO, 2008; AFONSO, 2009).

É a partir dessa naturalização da competição que a desigualdade se estabelece como fator intrínseco dessa lógica neoliberal, visto que as diferenças e as desigualdades não são consideradas nessa disputa pelos agentes, principalmente por aqueles responsáveis pela elaboração de políticas públicas:

Os usos que normalmente são feitos das comparações baseadas em resultados de exames e testes estandardizados (nacionais e internacionais) não parecem ter como central a preocupação com políticas que promovam o combate às desigualdades subjacentes a essas mesmas estatísticas (AFONSO, 2009, p. 23 - 24).

Como se pode compreender, os rankings não levam a um tipo de preocupação com as unidades escolares que ficam mal posicionadas. Ao contrário, servem para que as unidades bem colocadas sejam disputadas e, assim, cada vez mais, se reproduzam como "boas". Seguindo essa lógica, o governo do estado do Ceará lança mão de medidas para garantir o "sucesso" dos estabelecimentos bem colocados, as quais serão discutidas no tópico seguinte. 


\section{A accountabulity influenciando políticas educacionais no Ceará}

Neste tópico, será discutida a noção de accountability, além das ações governamentais da rede estadual do Ceará na busca por sua implementação. Afonso (2009, p. 14) diz que "o conceito de accountability é, em geral, polissémico e denso". Por isso, o autor realiza sua própria contextualização teórico-conceitual, o que lhe faz associar a accountability "a três dimensões essenciais autónomas, mas fortemente articuladas (ou articuláveis): a avaliação, a prestação de contas e a responsabilização" (AFONSO, 2009, p. 14). O autor entende que a avaliação pode ser usada para "o desenvolvimento de processos de prestação de contas e de responsabilização" (AFONSO, 2009, p. 14). Ou seja: nessa perspectiva, o processo de accountability é bem maior e mais complexo do que aparenta, visto que geralmente é ligado unicamente a prestação de contas. Ademais, só é possível haver prestação de contas e responsabilização se os conhecimentos puderem ser medidos, isto é, se houver padronização dos conteúdos, a fim de comparar os rendimentos dos diversos sujeitos avaliados (AFONSO, 2009). Nesse sentido, as avaliações devem ser estandardizadas e ramificadas, como é o caso do ENEM, do SAEB e do SPAECE, que conseguem comparar os resultados de alunos e de escolas das várias regiões do Brasil ou de municípios do Ceará.

Sabendo disso, serão analisados documentos que indiquem o grau de inserção da rede estadual do Ceará na lógica da accountability. Inicialmente, destaca-se a importância dada por essa rede aos testes padronizados: pelo menos desde 2012, o governo do Ceará realiza "mutirão" pela inscrição de alunos no ENEM, o que levou o estado a ser destaque nacional em evolução de número de inscritos (ALUNOS..., 2012; BRAGA, 2017). As gestões escolares eram instadas a inscrever todos os alunos das $2^{\text {a }}$ e $3^{\text {a }}$ séries do ensino médio, apesar dos eufemismos contidos no site oficial da Secretaria de Educação do Estado do Ceará (doravante, SEDUCCE) acerca do projeto "ENEM chego junto chego bem" (ENEM..., [2014]), criado em 2012: o projeto "tem a finalidade de mobilizar, motivar e preparar os alunos da Rede Pública Estadual para a realização [do] Exame" (SAMPAIO, 2017). 
Em relação ao SPAECE, entre 2008 e 2013, uma média de 630 mil alunos nos níveis fundamental e médio das redes municipais e estadual realizaram o exame por ano (CEARÁ, 2013), o que indica sua importância para as políticas públicas no estado. Vale ressaltar também que o SPAECE é um exame próprio da rede estadual do Ceará criado na década de 1990, quando os testes padronizados ainda "engatinhavam" no país, o que aponta ainda mais a sua relevância. Como se pode perceber, a rede estadual aderiu cedo à lógica dos testes estandardizados e ainda hoje vem estimulando seu prosseguimento, como fica claro pelo projeto "ENEM chego junto chego bem". Isso aponta para a adesão à dimensão da avaliação, destacada por Afonso (2009).

Em relação à prestação de contas, governo e mídia se empenham em divulgar amplamente os rankings das escolas, após a divulgação dos resultados das avaliações. A SEDUC-CE, por exemplo, divulgou a seguinte notícia em seu sítio oficial:

A rede pública cearense ganhou lugar de destaque nos resultados do ENEM de 2014 divulgados nesta quarta-feira (5) pelo Instituto Nacional de Estudos e Pesquisas Educacionais Anysio Teixeira (INEP). Na classificação geral, a Escola Estadual de Ensino Profissional Adriano Nobre, de Itapajé, foi a instituição pública mais bem colocada no Estado (CAVALCANTE; LIMA, 2015, [s.p.]).

Apesar da divulgação do "destaque" e até do nome de algumas escolas bem posicionadas, a SEDUC-CE faz uma crítica ao ranqueamento de escolas, a saber: "as escolas precisam ser comparadas com outras que apresentam características de oferta e público atendido similares para que não haja o risco dos dados serem analisados de forma descontextualizada" (CAVALCANTE; LIMA, 2015, [s.p.]). Já na mídia, a divulgação ocorre geralmente com pouca ou nenhuma crítica: uma matéria da Globo, por exemplo, apresenta o ranking das 100 melhores escolas no exame e destaca ainda no subtítulo: "apenas duas são escolas públicas" (VEJA..., 2016, [s.p.]). No final da matéria há, entretanto, uma ressalva:

O [Ministério da Educação] MEC ressalta que a comparação de escolas apenas pela nota do Enem não é adequada, porque não leva em consideração outros fatores determinantes 
para a qualidade de ensino de cada instituição, como a formação [d]e professores, o tamanho da escola, a seleção de alunos e o padrão de vida das famílias dos estudantes. (VEJA..., 2016, [s.p.]).

Já uma matéria do jornal cearense Diário do Nordeste não conta com qualquer ressalva ao anunciar que "das 20 escolas com maiores médias em provas objetivas, cinco são do Ceará [...]. Dessas 20 melhores, todos são colégios particulares. Pelo segundo ano consecutivo, essa listagem não inclui escolas públicas" (ESCOLAS..., 2016, [s.p.]). A matéria ainda conclui que "os dados são divulgados anualmente pelo governo federal para fomentar o debate sobre a qualidade na educação" (ESCOLAS..., 2016, [s.p.]). Vale ressaltar ainda que o número de alunos por escola participante do ENEM pode contribuir para maior flutuação dos resultados. Segundo Andrade e Soida (2015, p. 262), "existe uma maior variabilidade [de resultados] entre as escolas com um menor número de alunos".

Também há vários sítios na internet que divulgam os rankings, principalmente do ENEM, sem qualquer tipo de discussão ou ressalva. Importa ressaltar que, a partir de 2018, o ranking por escolas do ENEM deixou de ser divulgado pelo MEC. Segundo o ministro da educação, "o ENEM não é um exame que possa permitir a avaliação adequada de cada unidade escolar, e quando se faz propaganda utilizando um ranqueamento indevido a partir de uma prova como essa, está se fazendo propaganda enganosa" (TOKARNIA, 2017, [s.p.]). A divulgação de resultados passou a se referir somente a cada candidato. Nesse sentido, as redes pública e privada estão se adequando a essa nova realidade.

Já em relação à responsabilização, o governo cearense também possui ações que a estimulam. Antes de qualquer coisa, é necessário destacar que a própria divulgação de rankings pode afetar alunos e professores no sentido de autorresponsabilização, embora os sujeitos avaliados possam perceber esse processo de maneira acrítica. Os constrangimentos por parte de quem está na parte de baixo da tabela e tem seu estabelecimento publicamente reconhecido como "ruim", no entanto, serão inevitáveis a partir da divulgação de cada ranking. Conforme destaca Melo (2008), 
professores percebem rankings como julgamento do mundo escolar e também do seu desempenho, assim como foi ressaltado anteriormente. De qualquer forma, a autorresponsabilização dos sujeitos escolares não será objeto de análise neste texto, devido aos métodos empregados.

Prosseguindo na análise da responsabilização, mais um dado será apresentado: o governo estimula a competição por meio de premiações aos melhores colocados no ranking. Alunos, professores e estabelecimentos recebem premiações e vantagens ao atingirem desempenho considerado satisfatório. O Programa Aprender Pra Valer, criado pela Lei Estadual N 14.190, de 30 de julho de 2008, "tem por finalidade a elevação do desempenho acadêmico dos alunos do ensino médio, com vistas à aquisição dos níveis de proficiência adequados a cada série/ano" (CEARÁ, 2008, [s.p.]). O texto inicial da lei não fala em premiação; pelo contrário, destaca ações de equipes de profissionais e elaboração de materiais didáticos para alcançar o objetivo desejado. Contudo, pouco mais de um ano depois de sua criação, uma nova lei criou a premiação aos alunos. A Lei Estadual No 14.483, de 08 de outubro de 2009, diz o seguinte:

Fica instituída a premiação de um microcomputador para os alunos das 3 (três) séries do ensino médio, das escolas da rede estadual de ensino do Ceará, que alcançaram as médias de proficiência adequadas em língua portuguesa e em matemática na avaliação de 2008 do Sistema Permanente de Avaliação da Educação Básica do Ceará - SPAECE (CEARÁ, 2009a, [s.p.]).

Atualmente, a premiação dos alunos está diretamente atrelada ao Programa Aprender Pra Valer. ${ }^{9}$ Em 2014, 20.155 alunos foram premiados com um computador. ${ }^{10}$ Isso representava cerca de 5\% do total de matrículas daquele ano na rede estadual, que foi de

9 A Lei $N^{\circ}$ 15.572, de 07 de abril de 2014, expandiu o leque de avaliação para o ENEM. A partir daquele ano, alunos da $2^{a}$ e da $3^{a}$ série do ensino médio que conseguem pontuação naquele exame igual ou superior a 540 e 560 pontos, respectivamente, ganham um computador (cf. CEARÁ, 2014).

10 De acordo com dados conseguidos com a Ouvidoria e Controladora Geral do Estado do Ceará, em 2013, foram 16.596 alunos premidos. Em 2015, 20.430 estudantes conseguiram o mesmo feito. Como se pode perceber, há regularidade no número de pessoas premiadas, variando de $4 \%$ a $5 \%$ do total de matrículas. 
393.413 (de acordo com dados gerados pela SEDUC-CE e pelo INEP referentes àquele ano), ou seja, uma reduzida "elite" de alunos. Essa porcentagem, inclusive, é muito próxima da de alunos resilientes encontrada entre "alunos socioeconomicamente carentes", que é de 6\%, segundo dados da Organização para a Cooperação e Desenvolvimento Econômico (OCDE):

Isso significa que, além de fatores externos ao aluno, tais como: escolaridade dos pais, situação de classe, ambiente social, há fatores internos, próprios à criança e ao adolescente, que os levam a desenvolver uma intensa vontade de aprender. Talvez, se trate desses 6\% de resilientes (HAGUETTE; PESSOA; VIDAL, 2016, p. 616).

Além dos estudantes, os trabalhadores das escolas também podem ser beneficiados com premiação pelo bom desempenho de seus alunos, a saber: a Lei Estadual No 14.484, também de 08 de outubro de 2009, instituiu o Prêmio Aprender Pra Valer, dessa vez, beneficiando o "quadro funcional" das escolas. O prêmio:

[...] visa reconhecer o mérito nas escolas da rede pública de ensino do Estado que alcançarem as metas anuais de evolução da aprendizagem dos alunos [...] [e] consiste na premiação do quadro funcional de todas as escolas que alcançarem as metas anuais de evolução da aprendizagem dos alunos do ensino médio, definidas pela Secretaria da Educação do Estado do Ceará - SEDUC, tendo por referência os resultados do Sistema Permanente de Avaliação da Educação Básica do Ceará SPAECE (CEARÁ, 2009b, [s.p.]).

O prêmio, pecuniário, é referente a um salário mensal de cada servidor, ou seja, o profissional recebe um $14^{\circ}$ salário anual. Vale ressaltar que todos os profissionais da escola são premiados, incluindo aqueles com contrato temporário e também os terceirizados. Em outubro de 2017, o governo do estado do Ceará anunciou que um novo projeto será criado, a fim de premiar escolas com os melhores resultados no SPAECE, substituindo o Prêmio Aprender Pra Valer (MADEIRA, 2017). Provavelmente, isso se deve ao fato de que o MEC deixou de ranquear as escolas pelo ENEM, conforme destacado acima. 
Outra forma de responsabilização ocorre por meio da ascensão funcional dos professores efetivos. A chamada "promoção sem titulação" dos docentes só é efetivada a 60\% do total de professores aptos a progredir, o que lhes garante um incremento de 5\% no salário (CEARÁ, 2016a). Para ficar no grupo de beneficiados, o professor necessita passar por uma avaliação de desempenho em que $20 \%$ da nota final é referente ao "resultado escolar" que é calculado a partir da nota média dos alunos no ENEM, além do percentual de participação dos alunos nesse exame e da evolução da nota de um ano para outro ${ }^{11}$ (CEARÁ, 2016b). Dessa forma, uma maneira de o professor tentar garantir a promoção funcional é por meio do resultado satisfatório de seus alunos no ENEM. Todavia, novamente se ressalta que isso desconsidera as diferenças e desigualdades entre as escolas e os contextos individuais de alunos e professores.

Como se pode perceber pelas análises realizadas acima, a rede estadual do Ceará aderiu de forma rigorosa à accountability, principalmente às dimensões da avaliação e da responsabilização, que contaram com uma forte e disseminada adesão por aquela rede. Em relação à dimensão da prestação de contas, apesar de o governo também ter aderido a esta, a adesão veio acompanhada de relativa crítica à lógica dos rankings. De qualquer forma, esta última é a dimensão que o governo menos precisa se empenhar em efetivar, visto que a mídia e as redes sociais na internet geralmente são aplicadas e mais ramificadas em divulgar tais rankings; muitas vezes, sem qualquer tipo de crítica, conforme foi indicado.

Nesse sentido, as três dimensões da accountability são "autônomas", mas fácil e fortemente articuladas (ou articuláveis) (AFONSO, 2009), visto que se retroalimentam. O Estado, como instituição estrutural que é, contribui significativamente para essa articulação ao agir nas três dimensões de forma a tornar coerentes umas em relação às outras. Só com a ampla participação de estudantes e escolas nas avaliações em larga escala, é possível realizar o trabalho de prestação de contas. Havendo ampla prestação de contas com aspecto aparente de universal, abre-se caminho para a responsabilização, pois todos os sujeitos

11 Um quarto fator é o fluxo escolar dos alunos. 
e estabelecimentos educacionais são equiparados acriticamente como iguais. Havendo, por fim, a responsabilização, completa-se o ciclo da "qualidade" educacional, visto que se formam os rankings e, a partir destes, as noções de bom-ruim, prêmio-castigo, mérito-demérito etc. A tendência, conforme indica a legislação citada anteriormente, é que essas noções se aprofundem e criem efeitos perversos. Como destacam Souza e Oliveira (2003, p. 875): "a avaliação [acrescida da prestação de contas e da responsabilização] torna-se então um mecanismo indutor de excelência e, como desdobramento, naturaliza-se a desigualdade". Isso é o que será discutido a seguir.

\section{Possíveis efeitos da accountability na educação escolar cearense}

Com a articulação das três dimensões da accountability sendo proporcionada centralmente pelo Estado, as noções antagônicas bom-ruim, prêmio-castigo e mérito-demérito acabam por provocar efeitos na sociedade: nas mães e nos pais de estudantes, em governantes, em pesquisadores etc. Dito isso, serão discutidos alguns possíveis efeitos da accountability na educação escolar cearense.

Inicialmente, destacam-se os "efeitos de mercado" e os "efeitos de quase-mercado", a saber: o governo realiza seleção de alunos em suas escolas com melhores resultados. Nas escolas profissionalizantes, por exemplo, onde os alunos têm nove aulas diárias e três refeições, há seleção por meio de análise do histórico escolar do ensino fundamental, prevalecendo o aluno com as melhores notas. Uma vaga nesse tipo de escola é tão disputada que o governo precisou criar um limite de ocupação de 20\% para alunos provenientes de escolas privadas (CEARÁ, 2011), pois a demanda desse público por vaga é grande. Já nas escolas militares, há seleção por prova, em que os melhores colocados conseguem vaga, além de haver reserva de vaga para filhos de militares (EDITAL..., 2017). Dessa forma, as melhores escolas nos rankings conseguem a adesão dos melhores alunos, o que gera um tipo de 
"círculo virtuoso educacional"12. Dito isso, as demais escolas, as mal posicionadas, ficam com a "sobra", isto é, com os alunos que não conseguiram vaga nas "boas" escolas por não terem o desempenho considerado satisfatório. Nesse caso, há a formação de um tipo de "círculo vicioso educacional".

Além disso, há atualmente a prática comum do "marketing escolar" (GALVÃO; VIDAL; VIEIRA, 2016), que diz respeito à importação pelas escolas públicas de uma prática já consolidada entre as privadas: divulgação de resultados, principalmente de aprovação de alunos em universidades, por parte dos estabelecimentos educacionais. Isso ocorre geralmente por meio de cartazes e faixas, na fachada da escola ou espalhados pelo bairro onde o estabelecimento está localizado. O marketing escolar pode servir tanto como uma forma de o gestor tentar alavancar os resultados de seu estabelecimento, quanto como uma forma de disputar clientela com outros estabelecimentos (GALVÃO; VIDAL; VIEIRA, 2016).

Outra medida do governo é o financiamento diferenciado das escolas. Conforme destacam Souza e Oliveira (2003, p. 875), a "associação entre desempenho e financiamento" é uma forma de garantir a competição entre escolas e sistemas de ensino, pois cria critérios de alocação de recursos relacionados ao desempenho. Novamente, as escolas profissionalizantes têm vantagem ao terem base de financiamento diversificada em relação às escolas regulares. ${ }^{13}$ Até a alimentação dessas escolas possui recursos próprios do governo do estado, o que lhes garante refeições com valores maiores - o que se traduz em maior quantidade e

12 Em 2009, das 45 escolas contempladas pelo Prêmio Aprender Pra Valer, $70 \%$ eram profissionalizantes ou militar (apenas uma deste tipo). Em 2010, cerca de $75 \%$ das 29 escolas premiadas eram profissionalizantes. Em 2011, houve um revés, sendo apenas 20\% profissionalizantes das 14 escolas premiadas. Todavia, em 2012, 67\% das 9 escolas agraciadas eram daquele tipo. Em 2013, 1 das 3 premiadas era profissionalizante. A partir de 2014, o prêmio contou com mudanças para a inclusão da nota do ENEM.

13 De acordo com dados obtidos do Portal da Transparência do Ceará, além do financiamento comum a todas as escolas de ensino médio, as escolas profissionalizantes possuem outra fonte de financiamento, específica para esse tipo de estabelecimento. Em 2017, por exemplo, essa segunda fonte previu um investimento extra de $\mathrm{R} \$ 114$ milhões para aquelas escolas. Isso significa uma média de R\$ 1 milhão para cada um dos 115 estabelecimentos daquele tipo. 
variedade - do que em outros estabelecimentos ${ }^{14}$. As escolas militares também possuem financiamento diferenciado, tendo recursos tanto da SEDUC-CE, quanto da Secretaria de Segurança Pública e Defesa Social (SSPDS) (HAGUETTE; PESSOA, 2015).

Além disso, também há as premiações diferenciadas, que já foram discutidas anteriormente e serão retomadas. A lei que regulamenta os prêmios discrimina seus objetivos da seguinte forma:

Art. $4^{\circ}$ São objetivos do Prêmio:

I - estimular os gestores, professores e os demais servidores da escola na implementação de um projeto pedagógico que possibilite a todos os alunos do ensino médio a permanência na escola e o alcance dos níveis de proficiência adequado para cada série nas diversas áreas do conhecimento;

II - reconhecer o trabalho de todos os profissionais da educação das escolas que apresentam bons resultados de aprendizagem dos alunos;

III - dar visibilidade às escolas com experiências exitosas e passíveis de replicabilidade em outras escolas da rede estadual (CEARÁ, 2009b, [s.p.]).

Como se pode perceber, os objetivos são amplos e audaciosos, o que levanta a questão de se o governo está conseguindo atingir tais fins. Nesse sentido, será realizada uma breve análise de dados que possam esclarecer esse questionamento. Inicialmente, será realizada análise do número de matrículas da rede estadual, a fim de se verificar se a lógica da premiação está contribuindo para a permanência do aluno na escola, um dos objetivos daquele prêmio. Considerando que essa política teve início em 2009, serão analisados os dados entre 2010 e 2016. O número de matrículas na

14 Vale ressaltar que durante a greve dos professores da rede estadual de 2016, centenas de alunos ocuparam escolas e protestaram contra o governo pelas suas demandas. A principal delas era a merenda escolar, que custava R\$ 0,30 por aluno, o que se refletia em uma alimentação ruim, na avaliação dos alunos ocupantes. O governo atendeu parcialmente essa demanda ao destinar alguns milhões de reais para a aquisição de alimentos destinados à merenda escolar (cf. GOMES, 2016). 
rede estadual do Ceará caiu de forma abrupta, havendo diminuição absoluta de quase 80 mil matrículas, tendo aumento apenas no último ano do intervalo:

Tabela 01 - Matrículas na educação básica na rede estadual do Ceará em todos os níveis de ensino, entre 2010 e 2016.

\begin{tabular}{|l|l|l|l|l|l|l|l|}
\hline Ano & $\mathbf{2 0 1 0}$ & $\mathbf{2 0 1 1}$ & $\mathbf{2 0 1 2}$ & $\mathbf{2 0 1 3}$ & $\mathbf{2 0 1 4}$ & $\mathbf{2 0 1 5}$ & $\mathbf{2 0 1 6}$ \\
\hline $\begin{array}{l}\text { Matrículas abso- } \\
\text { lutas } \\
\text { (em milhares) }\end{array}$ & 522 & 521 & 503 & 486 & 462 & 432 & 445 \\
\hline $\begin{array}{l}\text { Matrículas rela- } \\
\text { tivas }\end{array}$ & $100 \%$ & $100 \%$ & $96,4 \%$ & $93,1 \%$ & $88,5 \%$ & $82,7 \%$ & $85,2 \%$ \\
\hline
\end{tabular}

Fonte: Sinopse estatística elaborada a partir de INEP $(2011 ; 2012 ; 2013 ; 2014 ; 2015$; 2016 ; 2017).

Vale ressaltar que, nesse período, o governo do estado tentou transferir suas turmas de ensino fundamental para os vários municípios, como prevê a Lei de Diretrizes e Bases da Educação Nacional, mas essas turmas não foram absorvidas pelas redes municipais. Diante disso, têm-se os dados a seguir:

Tabela 02 - Evolução e relação no número de matrículas no ensino fundamental no Ceará nas redes estadual, municipal e privada nos anos de referência.

\begin{tabular}{|l|l|l|l|}
\hline Rede & $\mathbf{2 0 1 0}$ & $\mathbf{2 0 1 6}$ & Relação 2016/2010 \\
\hline Estadual & 96.534 & 37.943 & -58.591 \\
\hline Municipal & 1.142 .872 & 953.062 & -189.810 \\
\hline Federal & 522 & 429 & -93 \\
\hline Privada & 241.809 & 257.201 & +15.392 \\
\hline
\end{tabular}

Fonte: Sinopse estatística elaborada a partir de INEP $(2011 ; 2017)$.

Como se pode perceber, as matrículas no ensino fundamental da rede estadual diminuíram na ordem de 58 mil, passando para 37.943, em 2016. Todavia, esse número não foi absorvido pelas redes municipais, que tiveram uma queda mais expressiva ainda, na ordem de cerca de 190 mil matrículas, passando para 953 mil, em 2016. A rede privada também não absorveu todo esse quantitativo, apesar de ter crescido 15 mil matrículas no período. O que se observa é uma queda abismal no número de matrículas no ensino fundamental, o que indica que a queda de quase $80 \mathrm{mil}$ 
matrículas na rede estadual, ou 15\% do total, não tem relação com a transferência de responsabilidade para a esfera municipal, nem tem relação com possíveis "efeitos de mercado" com a absorção dos alunos pela rede privada.

Dessa forma, como a grande maioria do número de matrículas da rede estadual tem relação com o ensino médio, será este nível de ensino que será analisado a seguir. Dito isso, um dado que ajuda a esclarecer esse movimento de redução de matrículas tem relação com o tipo de aluno que deixou de frequentar a escola.

Tabela 03 - Evolução e relação no número de matrículas no ensino médio na rede estadual do Ceará, nos anos de referência, de acordo com a idade do público.

\begin{tabular}{|l|l|l|l|}
\hline & $\mathbf{2 0 1 0}$ & $\mathbf{2 0 1 6}$ & $\begin{array}{l}\text { Relação 2016/2010 } \\
\text { absoluta e relativa }\end{array}$ \\
\hline Até 17 anos & 260.071 & 301.600 & $+41.529(+16 \%)$ \\
\hline $\mathbf{1 8}$ anos ou mais & 151.105 & 78.266 & $-72.839(-48,4 \%)$ \\
\hline Total & 411.176 & 379.866 & $-31.310(-7,8 \%)$ \\
\hline
\end{tabular}

Fonte: Sinopse estatística elaborada a partir de INEP $(2011 ; 2017)$.

Como se pode perceber, a variação negativa no número de matrículas apenas no ensino médio da rede estadual foi de $7,8 \%$. Todavia, o tipo de aluno que abandonou a escola é bem específico: o aluno maior de idade, adulto (redução de 48\%) ou, para ser mais específico, o aluno fora da faixa etária que alavanca a taxa de distorção idade-série. ${ }^{15}$ Esse tipo de aluno, em geral, necessita conciliar estudo e emprego (formal ou informal), ${ }^{16}$ o que o "empurra" para o turno noturno. Isso converge com a evolução do número de matrículas nesse turno, como se pode acompanhar pela tabela seguinte:

15 De acordo com dados obtidos do Anuário Estatístico do Ceará produzido em 2017, vale ressaltar que, entre 2010 e 2015 (último ano com dados disponíveis), o número de adolescentes de 15 a 17 anos residentes no estado do Ceará passou de 525.633 para 489.488 (redução de 6,9\%), enquanto o número de jovens de 18 a 29 anos passou de 1.886 .937 para 1.802 .724 (redução de $4,5 \%$ ). Isto é, a evolução das matrículas escolares não seguiu o crescimento populacional em cada faixa etária, logo, o movimento das matrículas nos anos analisados não é uma consequência da evolução etária do estado.

16 Dados do SAEB 2013 indicam que 51\% dos alunos do turno noturno trabalham fora de casa. Em relação ao turno diurno, apenas 22\% dos estudantes estão na mesma situação (cf. IAS, 2015). 
Tabela 04 - Evolução e relação do número de matriculas no ensino médio no turno noturno na rede estadual do Ceará, nos anos de referência

\begin{tabular}{|l|l|l|l|}
\hline & $\mathbf{2 0 1 0}$ & $\mathbf{2 0 1 6}$ & $\begin{array}{l}\text { Relação 2016/2010 } \\
\text { absoluta e relativa }\end{array}$ \\
\hline $\begin{array}{l}\text { Matrículas no turno } \\
\text { noturno }\end{array}$ & 113.075 & 71.666 & $-41.409(-37,6 \%)$ \\
\hline Total de matrículas & 411.176 & 379.866 & $-31.310(-7,8 \%)$ \\
\hline $\begin{array}{l}\text { Relação relativa matrí- } \\
\text { cula total/noturno }\end{array}$ & $27 \%$ & $19 \%$ & $132 \%$ \\
\hline
\end{tabular}

Fonte: Sinopse estatística elaborada a partir de INEP $(2011 ; 2017)$.

As tabelas acima mostram que $132 \%$ das matrículas perdidas no ensino médio da rede estadual do Ceará são referentes ao turno noturno, pois houve uma redução absoluta de 31 mil matrículas, enquanto o turno noturno perdeu 41 mil matrículas. Este turno representava, em 2010, 27\% do total de matrículas, passando, em 2016, para apenas 19\%. O turno noturno, por abrigar muitos alunos trabalhadores e fora de faixa, além de geralmente ter uma hora-aula a menos por dia, ${ }^{17}$ é um turno "problemático" para os resultados apresentados à sociedade, para a prestação de contas, pois "derruba" o resultado geral das escolas. ${ }^{18}$

Um exemplo é exatamente a distorção idade-série que, no ensino médio, passou de 25,6\% para 19,5\%, entre 2010 e 2016, segundo dados da SEDUC-CE/ Coave/ Ceged/ Educacenso 2016. Essa redução significativa tem relação direta com a involução das matrículas no turno noturno e especificamente de alunos com 18

17 Dados do Censo Escolar 2013 indicam que o aluno do turno diurno tem, em média, 308 minutos diários de aula, ante 232 minutos no aluno do turno noturno. Uma diferença de 76 minutos. Considerando que uma aula geralmente conta com 50 minutos, o aluno diurno tem uma aula e meia a mais por dia (cf. IAS, 2015).

18 Dados da Avaliação Nacional da Educação Básica (ANEB) 2013, parte integrante do SAEB, indicam que escolas que ofertam tanto o turno diurno quanto o turno noturno apresentam grande variação de resultado de desempenho entre os alunos de cada turno: 24,1 pontos em português e 19,2, em matemática. A escala vai de 0 a 500 (cf. IAS, 2015). Segundo o INEP, a escala comporta 10 níveis de conhecimento, separados entre si por 25 pontos, logo, as diferenças de desempenho encontradas nos dados da ANEB 2013 indicam que os alunos do turno noturno estão cerca de um nível abaixo dos alunos do diurno em ambas as disciplinas. 
anos ou mais da idade, que, em quase todos os cenários, contribuem para o incremento da distorção idade-série, visto que a idade ideal para se concluir o ensino médio regular é 17 anos. Todavia, há algumas poucas situações em que essa idade pode aumentar, como, por exemplo, no caso do ensino médio normal, que tem quatro anos de duração. ${ }^{19}$

Devido à metodologia empregada na pesquisa, não é possível saber se a exclusão de jovens de 18 anos ou mais e de alunos que estudam no turno noturno é algo planejado, se é uma consequência não intencional da política de accountability, ou mesmo se é outro fenômeno. Dessa forma, mais estudos devem ser realizados, a fim de que haja entendimento sobre a constatação exposta neste texto.

\section{Considerações finais}

O texto apresentado leva à constatação de que, dentro da lógica neoliberal do accountability, o governo do Ceará acabou por excluir da educação escolar a parcela da população mais vulnerável e que mais precisa de apoio para conseguir os níveis considerados satisfatórios de educação: os jovens a partir de 18 anos e que estudavam no turno noturno, a "sobra", conforme destacado no texto. Isso findou por alavancar alguns resultados escolares que servem para a prestação de contas do governo, como, por exemplo, a taxa de distorção idade-série.

A lógica empregada pelo governo estadual é incoerente com seus próprios objetivos, visto que, segundo a letra da lei, os prêmios distribuídos deveriam contribuir para a "permanência na escola" do alunado. Ademais, as premiações também deveriam contribuir para que "experiências exitosas" de algumas escolas pudessem ser replicadas em outras. O que se verifica, porém, é uma competição injusta entre estabelecimentos, visto que escolas exitosas possuem financiamento diferenciado e realizam seleção de alunos, o que

19 Segundo a Sinopse Estatística da Educação Básica 2016, no Ceará, apenas $0,6 \%$ das matrículas no ensino médio eram referentes à $4^{a}$ série ou a turmas não seriadas. 
contribui para o que chamamos de "círculo virtuoso educacional", enquanto as escolas não-exitosas têm financiamento ordinário e ficam com a "sobra" dos alunos daqueles estabelecimentos, configurando um "círculo vicioso educacional". Como quebrar essa lógica, a fim de que todos os estabelecimentos educacionais e todos os alunos possam ter condições igualitárias nessa disputa? Esse questionamento pode servir para embasar novos estudos.

Em suma, percebe-se que muito ainda deve ser pesquisado sobre esse assunto, a fim de que possa haver maior entendimento sobre a influência das políticas de accountability na educação escolar. Isso importa, porque a relação entre as práticas gerencialistas e a efetivação do direito à educação escolar tem sido a realidade não só do estado do Ceará, mas uma tendência da educação hodierna em todo o território nacional.

\section{REFERÊNCIAS}

AFONSO, A. J. Nem tudo o que conta em educação é mensurável ou comparável: crítica à accountability baseada em testes estandardizados e rankings escolares. Revista Lusófona de Educação, Lisboa, n. 13, p. 1329, 2009.

ALUNOS da rede estadual batem recorde de inscrições no ENEM. Secretaria da Educação do Estado do Ceará, Fortaleza, 29 jun. 2012. Disponível em: http://www.seduc.ce.gov.br/index.php/comunicacao/ noticias/129-noticias-2012/4631-alunos-da-rede-estadual-batemrecorde-de-inscricoes-no-enem. Acesso em: 09 mai. 2018.

ANDRADE, E.; SOIDA, I. A qualidade do ranking das escolas de ensino médio baseado no ENEM é questionável. Estudos Econômicos, São Paulo, v. 45, n. 2, p. $253-286,2015$.

BRAGA, L. Com recorde de inscrição no Enem, Ceará oferece transporte e lanche gratuitos para candidatos. Estadão, São Paulo, 12 nov. 2017. Disponível em: http://educacao.estadao.com.br/noticias/geral,comrecorde-de-inscricao-no-enem-ceara-oferece-transporte-e-lanchegratuitos-para-candidatos,70002081745. Acesso em: 09 mai. 2018.

BRASIL. Lei $\mathbf{N}^{\circ}$ 9.394, de 20 de dezembro de 1996. Lei de Diretrizes e Bases da Educação Nacional. Brasília: Congresso Nacional,1996. Disponível em: http://www.planalto.gov.br/ccivil_03/leis/19394.htm. Acesso em: 12 out. 2020. 
Ministério da Fazenda. Carga Tributária no Brasil 2014. Análise por tributos e bases de incidência. Brasília: CETAD, 2015.

CAVALCANTE, J.; LIMA, S. Escolas da rede pública estadual lideram rankings do ENEM 2014. Secretaria da Educação do Estado do Ceará, Fortaleza, 05 ago. 2015. Disponível em: http://www.seduc.ce.gov.br/ index.php/comunicacao/noticias/195-noticias-2015/9505-escolas-darede-publica-estadual-lideram-rankings-do-enem-2014. Acesso em: 09 mai. 2018.

CEARÁ. Lei $\mathbf{N}^{\circ} \mathbf{1 4 . 1 9 0}$, de 30 de julho de 2008. Cria o Programa Aprender Pra Valer que desenvolverá ações estratégicas complementares para o fortalecimento da aprendizagem dos alunos do ensino médio e sua articulação com a educação profissional e tecnológica. Fortaleza: Assembleia Legislativa do Estado do Ceará, 2008.

Lei $\mathbf{N}^{\mathbf{0}} \mathbf{1 4 . 4 8 3}$, de 08 de outubro de 2009. Institui a premiação para alunos do ensino médio com melhor desempenho acadêmico nas escolas da rede pública de ensino do estado e dá outras providências. Fortaleza: Assembleia Legislativa do Estado do Ceará, 2009a.

Lei $\mathbf{N}^{\mathbf{0}} \mathbf{1 4 . 4 8 4}$, de 08 de outubro de 2009. Institui o prêmio aprender pra valer, destinado ao quadro funcional das escolas da rede estadual de ensino, e dá outras providências. Fortaleza: Assembleia Legislativa do Estado do Ceará, 2009b.

Portaria $\mathbf{N}^{\circ}$ 1.053, de 19 de dezembro de 2011. Estabelece as normas para matrícula de alunos nas escolas públicas estaduais para o ano de 2012 e dá outras providências. Fortaleza: SEDUC - CE, 2011.

SEDUC. SPAECE - 2013. v. 3. Juiz de Fora: SEDUC, 2013

Lei $\mathbf{N}^{\circ} \mathbf{1 5 . 5 7 2}, 07$ de abril de 2014 . Altera o art. $1^{\circ}$ da Lei $\mathrm{N}^{\circ} 14.483$, de 8 de outubro de 2009. Fortaleza: Assembleia Legislativa do Estado do Ceará, 2014.

Decreto $\mathbf{N}^{\circ}$ 32.103, de 12 de dezembro de 2016. Regulamenta a promoção dos profissionais do Grupo Ocupacional Magistério da Educação Básica-MAG, estabelecida na Lei $n^{\circ} 12.066$, de 13 de janeiro de 1993, e as suas alterações posteriores, e dá outras providências. Fortaleza: Governo do estado do Ceará, 2016a.

Instrução Normativa SEDUC N001/2016-GAB/SEDUC, de 27 de dezembro de 2016. Estabelece normas e procedimentos operacionais para a promoção sem titulação dos profissionais do Grupo Ocupacional MAG da Educação Básica. Fortaleza: Governo do estado do Ceará, 2016b.

CELLARD, A. A análise documental. In: POUPART, Jean; DESLAURIERS, Jean-Pierre; GROULX, Lionel-H.; LAPERRIERE, Anne; MAYER, Robert; 
PIRES, Álvaro P. (Orgs.). et al. A pesquisa qualitativa: enfoques epistemológicos e metodológicos. Petrópolis - RJ: Vozes, 2014. p. 295-316.

EDITAL de Processo Seletivo do Colégio da Política Militar do Ceará General Edgard Facó 2018. CPMGEF, [online], 2017. Disponível em: http://cpmgef.com.br/wp-content/uploads/2017/11/Edital-ProcessoSeletivo-CPMGEF-2018.pdf. Acesso em: 22 nov. 2017.

ENEM chego junto chega bem. Secretaria da Educação do Estado do Ceará, Fortaleza, [2014]. Disponível em: http://www.seduc.ce.gov.br/ index.php/projetos-e-programas?id=8566:enem-chego-junto-chego-bem. Acesso em: 09 mai. 2018.

ESCOLAS do Ceará estão entre as melhores médias do Enem 2015; veja ranking. Diário do Nordeste, Fortaleza, 04 out. 2016. Disponível em: http://diariodonordeste.verdesmares.com.br/cadernos/cidade/online/ escolas-do-ceara-estao-entre-as-melhores-medias-do-enem-2015-vejaranking-1.1627903. Acesso em: 09 mai. 2018.

GALVÃO, W. N. M.; VIDAL, E. M.; VIEIRA, S. L. Marketing escolar, tendência emergente na política educacional? Reflexões de um estudo em escolas do Ceará. In: VIDAL, E. M.; VIEIRA, S. L. Políticas de ensino médio no Ceará: escola, juventude e território. Fortaleza: CENPEC, 2016. p. 175-184.

GOMES, N. O que desejam os estudantes que ocupam as escolas no Ceará. O Povo, Fortaleza, 22 mai. 2016. Disponível em: https://www20.opovo. com.br/app/opovo/dom/2016/05/21/noticiasjornaldom,3615817/ especial-o-que-desejam-os-estudantes-que-ocupam-as-escolas-no-ceara. shtml. Acesso em: 09 mai. 2018.

HAGUeTte, A.; PESSOA, M. K. M. Dez escolas, dois padrões de qualidade: uma pesquisa em dez escolas públicas de ensino médio do estado do Ceará. Fortaleza: Imprensa Universitária, 2015.

HAGUETTE, A.; PESSOA, M. K. M.; VIDAL, E. M. Dez escolas, dois padrões de qualidade: uma pesquisa em dez escolas públicas de ensino médio do estado do Ceará. Ensaio: avaliação e políticas públicas em Educação, Rio de Janeiro, v. 24, n. 92, p. 609 - 636, 2016.

IAS - Instituto Ayrton Senna. Ensino Médio noturno: uma análise da disparidade entre o aprendizado dos alunos e a qualidade de ensino no período da noite em comparação com o turno matutino. São Paulo: IAS, 2015.

INEP - Instivtuto Nacional de Estudos e Pesquisas Educacionais Anísio Teixeira. Sinopse Estatística da Educação Básica 2010. Brasília: MEC, 2011. Sinopse Estatística da Educação Básica 2011. Brasília: MEC, 2012. 
Sinopse Estatística da Educação Básica 2012. Brasília: MEC, 2013. Sinopse Estatística da Educação Básica 2013. Brasília: MEC, 2014. Sinopse Estatística da Educação Básica 2014. Brasília: MEC, 2015. Sinopse Estatística da Educação Básica 2015. Brasília: MEC, 2016. Sinopse Estatística da Educação Básica 2016. Brasília: MEC, 2017.

LIMA, L. O paradigma da educação contábil: políticas públicas educativas e perspectivas gerencialistas no ensino superior em Portugal. Revista Brasileira de Educação, Rio de Janeiro, n. 4, p. 43 - 59, 1997.

MADEIRA, V. Estado anuncia concurso e incentivos à educação. Diário do Nordeste, Fortaleza, 10 out. 2017. Disponível em: http://diariodonordeste. verdesmares.com.br/cadernos/cidade/estado-anuncia-concurso-eincentivos-a-educacao-1.1833356. Acesso em: 09 mai. 2018.

MELO, Maria Benedita Portugal e. Representações de professores do ensino secundário a propósito dos rankings escolares: notas de uma pesquisa empírica. Vírus, Lisboa, n. 3, p. 11 - 192008.

PAULA, A. P. P. de. Administração pública brasileira entre o gerencialismo e a gestão social. Revista de Administração de Empresas, São Paulo, v. 45, n. 1, p. 36-49, 2005.

PEREIRA, L. C. B. A reforma do Estado dos anos 90: lógica e mecanismos de controle. Brasília: Ministério da Administração Federal e Reforma do estado, 1997.

SAMPAIO, J. Enem 2017: escolas auxiliam alunos na inscrição para o exame. Secretaria da Educação do Estado do Ceará, Fortaleza, 08 mai. 2017. Disponível em: http://www.ceara.gov.br/2017/05/08/enem2017-escolas-auxiliam-alunos-na-inscricao-para-o-exame/. Acesso em: 09 mai. 2018.

SISTEMA de Avaliação da Educação Básica (SAEB). INEP, [online], [2017?]. Disponível em: http://portal.inep.gov.br/educacao-basica/saeb. Acesso em: 24 out. 2017.

SOUZA, S. Z. L. de; OLIVEIRA, R. P. de. Políticas de avaliação da educação e quase mercado no Brasil. Educação \& Sociedade, Campinas, v. 24, n. 84, p. 873 - 895, 2003.

TOKARNIA, M. MEC determina fim do Enem por escola; prova foca na seleção do ensino superior. Agência Brasil, Brasília, 11 mar. 2017. Disponível em: http://agenciabrasil.ebc.com.br/educacao/noticia/2017-03/mecdetermina-fim-do-enem-por-escola-prova-foca-na-selecao-do-ensino. Acesso em: 09 mai. 2018. 
VEJA as 100 escolas do Ceará com maiores médias no Enem 2015. G1 Globo, São Paulo, 05 out. 2016. Disponível em: http://g1.globo. com/ceara/noticia/2016/10/veja-100-escolas-do-ceara-com-maioresmedias-no-enem-2015.html. Acesso em: 09 mai. 2018. 